\title{
Lingual haematoma after treatment with alteplase (recombinant tissue plasminogen activator) for acute myocardial infarction
}

\author{
Stephen R McMechan, Brian Morrow, Norman P S Campbell
}

\author{
Regional Medical \\ Cardiology Centre, \\ Royal Victoria \\ Hospital, Belfast \\ Northern Ireland \\ S R McMechan \\ N P S Campbell \\ Regional Intensive \\ Care Unit, Royal \\ Victoria Hospital, \\ Belfast, Northern \\ Ireland \\ B Morrow \\ Correspondence to: \\ Dr S R McMechan, Regional \\ Medical Cardiology Centre, \\ Royal Victoria Hospital, \\ Grosvenor Road, Belfast, \\ BT12 6BA, Northern \\ Ireland. \\ Accepted for publication \\ 25 January 1995
}

Figure 3 Anterior view of neck showing signs of soft tissue bruising.

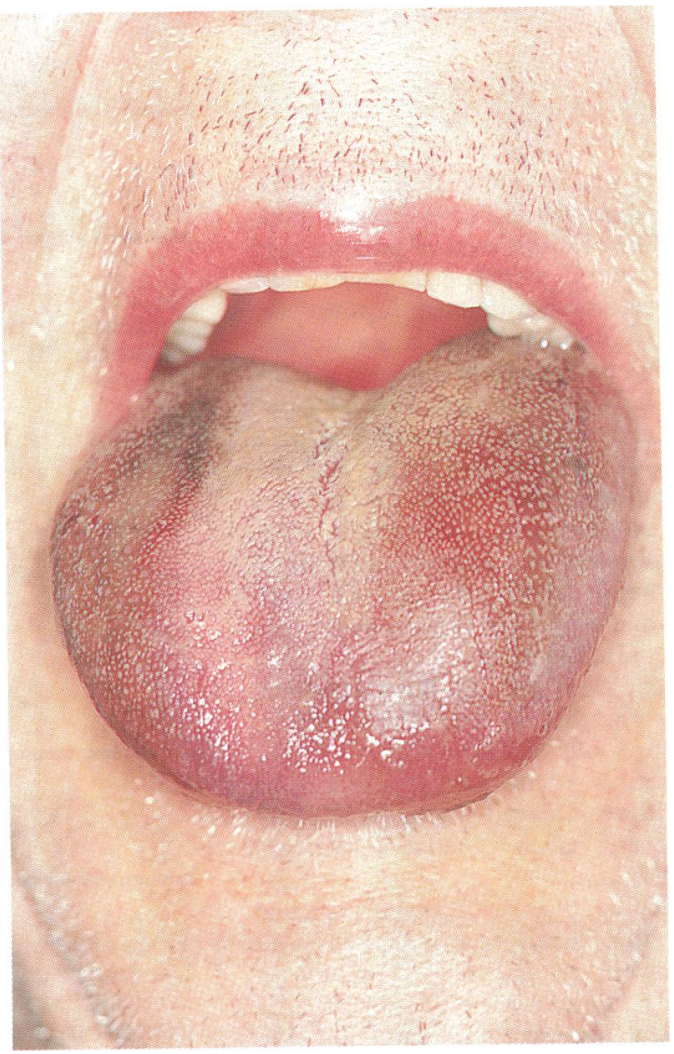

Figure 1 Anterior view of tongue haematoma 24 hours after onset.

A 69 year old previously healthy man was admitted with a 40 minute history of chest pain. The electrocardiograph showed evidence of an acute anterolateral myocardial infarction (MI). He was treated with soluble aspirin (300 $\mathrm{mg}$ ), heparin (5000 units bolus), alteplase (rtPA) (100 mg), and heparin infusion (1000 units/h).

An hour and 50 minutes later he complained of a dry mouth and examination showed considerable swelling and discolouration of the tongue and floor of the mouth, with the tongue occupying about $75 \%$ of the oral cavity. The appearances were consistent with

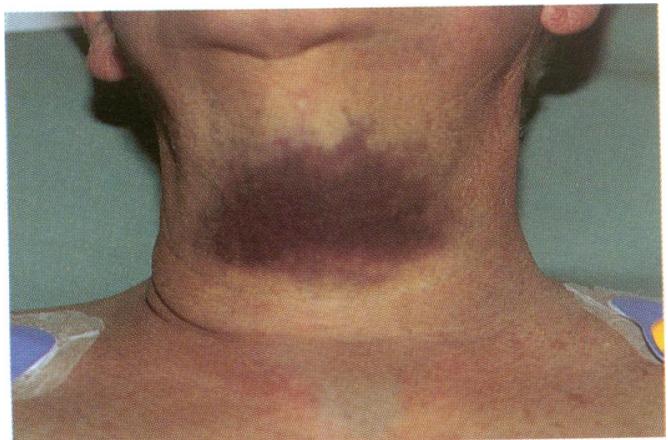

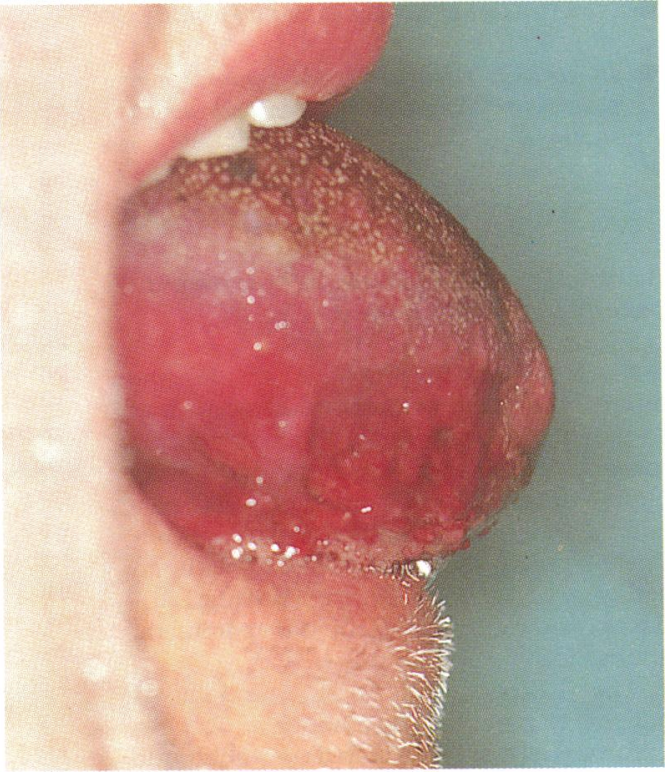

Figure 2 Lateral view of tongue haematoma 24 hours after onset.

an extensive spontaneous lingual haematoma (figs 1 and 2). There had been no trauma or instrumentation in the mouth. The patient could not speak clearly but did not have dyspnoea or stridor. The activated partial thromboplastin time was $95 \cdot 2$ seconds and the plasma fibrinogen concentration was $1.94 \mathrm{~g} / 1$ (normal ranges $29-40 \mathrm{~s}$ and $2-5 \mathrm{~g} / 1$ respectively). The heparin infusion was stopped and protamine (45 mg) given.

The patient was transferred to the intensive care unit where he was observed to see whether he needed intubation. Respiratory distress did not develop. Recovery was uneventful and bruising in the soft tissue of the anterior neck and submandibular areas persisted for 10 days (fig 3).

Haemorrhage into the tongue is a very rare complication of thrombolysis. It has been reported after streptokinase treatment for acute MI. ${ }^{1}$ The patient should be managed in a unit with facilities for complex intubation techniques.

Although swelling of the tongue after thrombolytic treatment may indicate anaphylaxis (which is well recognised with streptokinase but has also been reported with alteplase $\mathrm{e}^{2}$, the possibility of lingual haematoma should be considered.

1 Williams PJ, Jani P, McGlashan J. Lingual haematoma following treatment with streptokinase and heparin anesthetic management. Anaesthesia 1994;49:417-8.

2 Purvis JA, Booth NA, Wilson CM, Adgey AA, McCluskey DR. Anaphylactoid reaction after injection of alteplase. Lancet 1993;341:966-7. 